\title{
Balanceren en experimenteren
}

\section{Wetenschap en praktijk van publiek management ${ }^{*}$}

\author{
Sandra Groeneveld
}

Publieke organisaties en hun managers kunnen het niet snel goed doen. Dit wordt nog eens onderstreept door recent onderzoek van mijn collega's. Zij tonen op basis van een survey-experiment en focusgroepen aan dat burgers sterker negatief reageren op falende dienstverlening en minder positief op goede dienstverlening door publieke dienstverleners, vergeleken met dezelfde dienstverlening door private aanbieders (Van den Bekerom, Van der Voet \& Christensen, 2019). En ook wanneer wij voor scholieren een proefcollege publiek management verzorgen, hoeven we maar weinig moeite te doen om te laten zien dat publiek management niet alleen het dagelijks leven van burgers raakt, maar ook dat de betrokken organisaties en managers vaak kritiek krijgen.

Verwachtingen die burgers en politiek van publieke organisaties hebben, zijn niet alleen hoog, maar vaak ook tegenstrijdig. Enkele voorbeelden die recentelijk het nieuws haalden. UWV, Sociale Verzekeringsbank en Belastingdienst moeten toegankelijk zijn voor burgers en goede dienstverlening bieden, maar ook strikt handhaven en fraudeurs ontmaskeren. De politie moet efficiënter werken, maar ook in de haarvaten van de wijk zitten. En rond de wijkteams in het sociaal domein is de spanning tussen maatwerk en gelijke behandeling een terugkerende discussie. Voor bestuurskundigen zijn deze tegenstrijdigheden niet nieuw. Er is bovendien toenemende aandacht voor hoe die verschillende en soms tegenstrijdige eisen uitpakken op de werkvloer van publieke organisaties. Voor welke dilemma's publieke managers zich daardoor gesteld zien en hoe daarin te navigeren, daarvoor is minder aandacht. Het is een zoektocht naar nieuwe manieren van organiseren die publieke organisaties in staat stellen om aan veranderende en soms tegenstrijdige eisen tegemoet te komen. Over die zoektocht, hoe ons onderzoek daarbij kan helpen, wat dat betekent voor de relatie tussen wetenschap en praktijk en hoe studenten op die praktijk voor te bereiden, gaat deze bijdrage.

\section{Bureaucratie en onzekerheid}

In mijn oratie ben ik teruggegaan naar de kernfunctie van bureaucratie: onzekerheidsreductie (Weber, 1972; Gajduschek, 2003). Het gaat daarbij om de (on)zekerheid van de top van de organisatie, die verantwoording moet afleggen aan de politiek, die van de ambtenaar die zekerheid ontleent aan de kaders waarbinnen hij of zij inhoudelijke beslissingen neemt, en die van alle burgers die een

* Prof. dr. S.M. Groeneveld is hoogleraar Publiek Management bij het Instituut Bestuurskunde, Universiteit Leiden. 
betrouwbare overheid ontmoeten. Bureaucratie zorgt voor onzekerheidsreductie over het verleden - het gedrag van de overheid en haar ambtenaren is navolgbaar en daarmee controleerbaar - en de toekomst - het handelen van de overheid is voorspelbaar.

Organisatiekundig bezien is bureaucratie in veel situaties echter niet de meest effectieve structuur voor publieke organisaties. Dit omdat dynamiek en diversiteit in de omgeving en de complexiteit en onderlinge verwevenheid van de taken vragen om een flexibele en om een gedecentraliseerde inrichting van de organisatie. Met andere woorden om een organisatie die kan omgaan met onzekerheid of die zelfs kan omarmen: het tegendeel van bureaucratie. Ik noemde dit de ambivalentie van publiek management: het bestuurskundig belang van bureaucratie tegenover de organisatiekundige onvolkomenheid ervan (Groeneveld, 2016).

Er wordt natuurlijk al veel langer gefilosofeerd over organisatievormen die de overheid in staat moeten stellen om zich aan te passen aan, of liever nog in te spelen op veranderingen en toenemende diversiteit in de samenleving. Paul 't Hart (2014) beschrijft in zijn studie naar ambtelijk vakmanschap 3.0 een organisatiemodel dat 'plat' en 'poreus' is, dat wil zeggen een gedecentraliseerde organisatie die samenwerkt met tal van stakeholders over de grenzen van de organisatie heen. Van recenter datum is de studie van de Studiegroep Openbaar Bestuur (2016), 'Maak verschil', die wijst op het belang van adaptief vermogen en verbindend vermogen bij de inrichting van publieke organisaties voor de effectiviteit van de overheid.

Deze studies belichten een belangrijke kant van het verhaal. Ze geven echter geen antwoord op de vraag hoe tegelijkertijd onzekerheidsreductie georganiseerd kan worden, ofwel hoe de bureaucratische waarden van controleerbaarheid en voorspelbaarheid gegarandeerd blijven. De structurele reflex is in de publieke sector doorgaans sterk: structuren bedenken en regels maken is over het algemeen het eerste aangrijpingspunt om snel en zichtbaar zekerheid te bieden. Het kan er zelfs toe leiden dat een voormalig bewindspersoon zich afvraagt hoe het kan dat sommige regels waarvan zij toch zeker wist dat die waren afgeschaft - namelijk de vijf-minuten-registratie in de thuiszorg en wel door haar - op de werkvloer hardnekkig in stand bleven (Bussemaker, 2019). Die reflex wordt verder versterkt in situaties waarin het misgaat en die in de media breed worden uitgemeten, omdat dan, zoals het onderzoek van Van den Bekerom et al. (2019) impliceert, het vertrouwen in de overheid onder hoge druk komt te staan. Maar daarmee verliest de organisatie automatisch aan vermogen om zich aan te passen, samen te werken en te innoveren. Deze reflex verklaart waarom initiatieven om te dereguleren en anders te organiseren in de praktijk zo moeilijk van de grond komen.

Bestuurskundigen zouden zich dus wat meer moeten bekommeren om hoe in publieke organisaties wordt omgegaan met de dilemma's die 'ontregelen' met zich meebrengt (zie bijvoorbeeld Raaphorst, 2017). Om die reden heb ik ook gepleit voor meer inbreng uit de organisatie- en managementwetenschappen dan nu het geval is (Andrews \& Esteve, 2015). Deze disciplines kunnen inzicht geven in ver- 
schillende manieren waarop onzekerheidsreductie - controleerbaarheid en voorspelbaarheid - georganiseerd kan worden. De hypothese die ik in mijn oratie uiteen heb gezet, is dat onzekerheid binnen gedecentraliseerde en organische structuren gemanaged kan worden (vergelijk Piore, 2011), maar dat dit vereist dat we meer aandacht besteden aan gedrag en aan leiderschap.

\section{Structuur en gedrag}

Een overheid die en betrouwbaar en efficiënt en innovatief is, willen we allemaal wel. We kunnen ook steeds beter onder woorden brengen hoe een publieke organisatie die daaraan voldoet, eruit moet zien. Van der Steen, Scherpenisse \& Van Twist (2015) gebruiken daarvoor bijvoorbeeld de term 'meervoudig organiseren' om tot uitdrukking te brengen dat het gaat om de cumulatie van waarden, de opeenstapeling van daarmee verbonden eisen en het gegeven dat de organisatie tegelijkertijd daarmee moet kunnen omgaan. Zij illustreren dit aan de hand van een organisatie die in kleine stappen toewerkt naar het normaliseren van het werken in netwerken, wat noodzakelijk is geworden als gevolg van druk van 'onderop' en 'buitenaf. Het gaat er volgens de auteurs om dat deze nieuwe praktijk zich in de organisatie ontwikkelt bovenop andere die al naar gelang de behoefte kunnen worden ingezet. Wat opvalt in deze bestuurskundige studie, is enerzijds de nadruk op gedrag en de ontwikkeling van gedragspatronen, en anderzijds het zo goed als ontbreken van verwijzingen naar studies in de management- en organisatiewetenschappen. Dit terwijl deze verschillende theorieën en concepten bieden die kunnen helpen om de processen en onderliggende factoren in deze studie systematisch te onderzoeken, zoals taak-, doel- en externe afhankelijkheid, ambidexteriteit en geplande versus emergente verandering.

Een in de praktijk van publiek management actueel thema dat hier als illustratie kan dienen, is opgavegericht werken. Het is de nieuwe hype onder de sturingsfilosofieën. Het gaat daarbij met name om het bereiken van maatschappelijke impact door werk te organiseren rond maatschappelijke opgaven, zowel binnen de organisatie als in de samenwerking tussen organisaties. Een mooi voorbeeld van een poging om opgavegericht werken in de praktijk te brengen is het programma Koers en kansen voor de sanctie-uitvoering van het ministerie van Justitie en Veiligheid. In dit programma werken zorg, justitie en gemeenten samen om de effectiviteit van de sanctie-uitvoering te vergroten. Het programma biedt ruimte voor projecten die nieuwe werkwijzen ontwikkelen en evalueren. Daarmee is tijdelijke experimenteerruimte gecreëerd om nieuwe manieren van werken te ontdekken (vergelijk Van de Walle, 2009). En hoe inspirerend al deze projecten ook zijn, het programma staat ook voor de ingewikkelde opdracht om van deze projecten te leren hoe ze werkwijzen duurzaam kunnen veranderen. Dat vraagt om onderzoek naar de condities in de deelnemende organisaties en onder de betrokken professionals die het verspreiden van deze innovaties en het bestendigen ervan bevorderen of belemmeren. 


\section{Publiek management en leiderschap}

Werken volgens de bedoeling is een vergelijkbaar streven dat steeds meer publieke organisaties willen omarmen. Het komt erop neer dat publieke organisaties hun werkwijzen zo willen veranderen dat de maatschappelijke meerwaarde van het werk voorop komt te staan. Geïnspireerd door populaire managementboeken staan publieke managers voor de vraag hoe zij dat in hun bijzondere situatie voor elkaar kunnen krijgen. Het afgelopen jaar hebben we vanuit het Leiden Leadership Centre onderzoek gedaan naar factoren die werken volgens de bedoeling mogelijk maken of juist belemmeren (Schmidt, Kuipers, et al., 2019).

In dit onderzoek zagen we dat er een belangrijke rol voor leiderschap is weggelegd. Die rol heeft in de eerste plaats te maken met het formuleren en communiceren van de maatschappelijke meerwaarde waaraan het werk moet bijdragen (vergelijk Selznick, 1957). Het is de visionaire kant van leiderschap. Het publieke van publiek leiderschap schuilt er daarbij in dat leiderschap erop gericht moet zijn om in de organisatie, maar ook samen met externe stakeholders, tot een gezamenlijk gedragen definitie van die meerwaarde te komen (Hartley, Parker \& Beashel, 2018). Dat is niet altijd eenvoudig. Die definitie wordt in eerste instantie bovendien sterk ingekleurd door politieke besluitvorming.

Een tweede opdracht voor het leiderschap is het wegnemen of aanpassen van belemmerende factoren, zoals verantwoordings- en incentivestructuren die werken volgens de bedoeling niet ondersteunen of zelfs kunnen tegenwerken. Het is immers niet mogelijk om gedragspatronen te veranderen als formele en informele structuren dit niet ondersteunen (Moynihan \& Landuyt, 2009). Grofweg komt dit neer op het voorkomen dat er te veel wordt teruggevallen op structuren die beheersing en controle vooropstellen. Dit vraagt veel van formeel leidinggevenden, omdat zij zelf als managers doorgaans nog altijd primair daarop worden afgerekend. Hiermee verbonden is dan ook het zorgen voor bestuurlijk draagvlak, met name voor die situaties dat het erop aankomt.

Nieuwe organisatievormen veronderstellen bovendien dat leiderschap gedeeld en verspreid wordt (Pearce, 2004). Dit wordt belangrijker naarmate de onderlinge afhankelijkheid met betrekking tot de doelen die bereikt moeten worden en de afhankelijkheid van stakeholders in de omgeving groter zijn (Kuipers \& Groeneveld, 2014). Dat zijn dus bij uitstek die situaties die we bij initiatieven rond opgavegericht werken tegenkomen. Het vraagt leiderschapsgedrag van medewerkers van wie dat voorheen niet werd gevraagd. De onzekerheid waarmee dit gepaard gaat, kan moeilijk zijn om mee om te gaan (Currie, Lockett \& Suhomlinova 2009), treffend verwoord door een van onze respondenten: 'Als je je aan de regels houdt, doe je het in elk geval niet verkeerd.' Het vraagt niet alleen om verandering bij medewerkers; ook van het leiderschap van formele leiders in de lijn wordt iets anders gevraagd. Als wij in gesprek zijn met bestuurders, blijkt keer op keer dat men het lastig vindt om op die manier over leiderschap na te denken, als een proces dat gedeeld en verspreid wordt, en hoe zij daaraan kunnen bijdragen. 


\section{Wetenschap en praktijk}

Bestuurskunde is de studie van het openbaar bestuur en hoe langer hoe meer van governance in bredere zin. Het is een interdisciplinair vakgebied dat in enkele decennia is uitgegroeid tot een eigen discipline. Bestuurskunde analyseert bestuur en beleid niet alleen, ze heeft ook altijd aandacht voor hoe het beter kan. Dit laatste wordt vaak aangevoerd in het pleidooi voor de verbinding met de praktijk en verklaart de heropleving van bestuurskunde als 'design science'.

Er zou in de loop van de tijd een kloof zijn ontstaan tussen wetenschap en praktijk. De (nieuwe generatie) academici zouden zich vooral bezighouden met de analyse van governance-vraagstukken met behulp van steeds gesofisticeerdere methoden en technieken, terwijl anderen buiten de ivoren toren van de universiteit met oplossingen in de weer zijn voor problemen in de praktijk. Eerder hebben collega's en ik echter al aangetoond dat het met die kloof wel meevalt, afgaande althans op de publicatiepatronen van bestuurskundigen (Groeneveld, Bouwman \& Van de Walle , 2015). Daaruit bleek dat de collega's die in de internationale wetenschappelijke tijdschriften publiceren, hun bevindingen ook delen in Nederlandse vaktijdschriften die zijn gericht op de praktijk.

Het ongemak in deze discussie ligt vermoedelijk niet zozeer aan de methoden en de internationale publicaties, maar aan het gevoel dat er toch een afstand zit tussen wat wetenschap en praktijk relevant vinden. In de afgelopen jaren heb ik ondervonden hoe belangrijk het is om me in mijn wetenschappelijke werk mede te laten inspireren door de praktijk. De bestuurskundige praktijk is in de eerste plaats de context waarbinnen we principes en patronen onderzoeken. We moeten die context kennen en snappen, om het onderzoek goed te kunnen doen. In tegenstelling tot de natuurwetenschappen zijn de verschijnselen die wij onderzoeken bovendien zelf voortdurend in verandering. Sterker nog, ons onderzoek draagt niet zelden bij aan die verandering, al is het maar omdat het (hopelijk) bij huidige en toekomstige publieke managers reflectie teweegbrengt over hun praktijk. Om beide redenen is het onontbeerlijk om als wetenschapper de verbinding met de praktijk te houden.

Dat betekent niet dat ik ben 'overgelopen' naar de andere kant. Ik zoek de betrokkenheid met de praktijk bij het vertalen van onderzoeksvragen en conceptuele kaders naar specifieke praktische omstandigheden en andersom. Dat is nodig om betekenisvolle kennis te kunnen genereren. Die kennis komt tot stand door onafhankelijk en transparant te zijn in de keuze van methoden en in de analyse. Soms is dat kwalitatief onderzoek om te begrijpen hoe gedrag tot stand komt in specifieke contexten. Soms is dat kwantitatief of experimenteel onderzoek om effecten te meten. Uiteindelijk is ook de praktijk immers het meest gebaat bij solide en valide onderzoek.

Omdat de verschijnselen die wij onderzoeken zelf in de loop van de tijd veranderen, kan bovendien een ander theoretisch perspectief of analyseniveau aan relevantie winnen. Ik denk dat dit geldt voor de studie van gedrag in organisaties en 
nieuwe manieren van organiseren in publiek management. Door de uitdagingen waarvoor de publieke sector staat, is de relevantie om naar dit mesoniveau te kijken toegenomen.

Mijn pleidooi voor meer aandacht voor gedrag moet overigens niet verward worden met de snel opkomende benadering van behavioral public administration (Grimmelikhuijsen, Jilke, Olsen \& Tummers, 2017). De opmars van psychologisch onderzoek naar de motivatie en het gedrag van individuele ambtenaren en individuele burgers geeft relevante inzichten. Maar sociale processen en de sociale structuur of gedragspatronen in publieke organisaties (Oldham \& Hackman, 2010) en de bijzondere context van publiek management dreigen in die benadering naar de achtergrond te verdwijnen (O’Toole \& Meier, 2015). Ik heb in deze bijdrage juist uiteen willen zetten wat daarvan de toegevoegde waarde is voor de bestuurskundige onderzoeksagenda.

\section{Publiek management nu en in de toekomst}

Afgelopen jaar publiceerden mijn collega's en ik het studieboek 'Publiek management' (Van Noort, Groeneveld, Van der Hoek, Schalk \& Van der Voet, 2018). We hebben daarin geprobeerd ons onderzoek te vertalen naar een boek dat inzicht geeft in de spanningen en dilemma's waarmee leidinggevenden van publieke organisaties in de dagelijkse praktijk te maken hebben. In het boek gaan we concreet in op hoe dilemma's zich manifesteren binnen de vele deelgebieden van publiek management, zoals netwerkmanagement, het managen van turbulentie en crises, verandermanagement, management van diversiteit en inclusiviteit en prestatiemanagement. Het hoofdstuk over verandermanagement bespreekt bijvoorbeeld verschillende benaderingen van planmatig en participatief veranderen, om vervolgens te analyseren hoe de politiek-bestuurlijke context vaak een planmatige veranderaanpak afdwingt, terwijl de interne omgeving van de organisatie om een participatieve aanpak vraagt. We gaan vervolgens in op de vraag hoe publieke managers deze dilemma's kunnen hanteren en wat de effecten van hun keuzes zijn op de prestaties van publieke organisaties.

Dit jaar gebruiken we dit boek voor het eerst in onze bacheloropleiding en willen we daarmee onze studenten duidelijk maken met welke dilemma's werken in een publieke context gepaard gaat en ze daarop voorbereiden. Mede dankzij de samenwerking in het Leiden Leadership Centre zijn we bovendien in staat om onze studenten in Den Haag al vroeg kennis te laten maken met de praktijk (en vice versa). We proberen zo te bouwen aan een universitaire praktijk op het gebied van publiek management en leiderschap waarbij wetenschappelijk onderzoek, onderwijs en de praktijk elkaar steeds inspireren. Het balanceren tussen uiteenlopende eisen en het experimenteren met managementpraktijken die daarbij kunnen helpen, staan daarbij centraal. 


\section{Literatuur}

Andrews, R., \& Esteve, M. (2015). Still like ships that pass in the night? The relationship between public administration and management studies. International Public Management Journal, 18(1), 31-60.

Bekerom, P. van den, Voet, J. van der, \& Christensen, J. (2019). Prestatiepercepties van burgers over publieke en private dienstverlening. Den Haag: Universiteit Leiden.

Bussemaker, J. (2019). Zorg als sociale kwestie. Oratie Universiteit Leiden.

Currie, G., Lockett, A., \& Suhomlinova, O. (2009). The institutionalization of distributed leadership: A 'Catch-22' in English public services. Human Relations, 62(11), 1735-1761.

Gajduschek, G. (2003). Bureaucracy: Is it efficient? Is it not? Is that the question? Uncertainty reduction: An ignored element of bureaucratic rationality. Administration \& Society, 34(6), 700-723.

Grimmelikhuijsen, S., Jilke, S., Olsen, A.L., \& Tummers, L. (2017). Behavioral public administration: Combining insights from public administration and psychology. Public Administration Review, 77(1), 45-56.

Groeneveld, S.G., Bouwman, R.B., \& Van de Walle, S. (2015). Is er een trade-off tussen wetenschappelijke impact en praktijkrelevantie? Een analyse van de publicaties van bestuurs- en politieke wetenschappers in Nederland (2006-2011). Bestuurskunde, 2015, 73-84.

Groeneveld, S.M. (2016). Het belang van bureaucratie: Omgaan met ambivalentie in publiek management. Oratie Universiteit Leiden.

Hart, P. 't. (2014). Ambtelijk vakmanschap 3.0: Zoektocht naar het handwerk van de overheidsmanager. Essay in opdracht van de Vereniging voor OverheidsManagement, Vereniging van Gemeentesecretarissen en Stichting IKPOB, mei 2014.

Hartley, J., Parker, S., \& Beashel, J. (2018). Leading and recognizing public value. Public Administration, advance online access.

Kuipers, B., \& Groeneveld, S. (2014). De kracht van high performance teams: Zes ingrediënten voor excellent presteren in de publieke sector. Amsterdam: Mediawerf.

Moynihan, D.P., \& Landuyt, N. (2009). How do public organizations learn? Bridging cultural and structural perspectives. Public Administration Review, 69(6), 1097-1105.

Noort, W. van, Groeneveld, S.M., Hoek, M. van der, Schalk, J., \& Voet, J. van der. (red.). (2018). Publiek management. Bussum: Uitgeverij Coutinho.

Oldham, G.R., \& Hackman, J.R. (2010). Not what it was and not what it will be: The future of job design research. Journal of Organizational Behavior, 31(2-3), 463-479.

O’Toole, L.J., \& Meier, K.J. (2015). Public management, context, and performance: In quest of a more general theory. Journal of Public Administration Research and Theory, 25(1), 237-256.

Pearce, C.L. (2004). The future of leadership: Combining vertical and shared leadership to transform knowledge work. Academy of Management Executive, 18(1), 47-57.

Piore, M.J. (2011). Beyond markets: Sociology, street-level bureaucracy, and the management of the public sector. Regulation \& Governance, 5, 145-164.

Raaphorst, N. (2017). Uncertainty in bureaucracy: Toward a sociological understanding of frontline decision making. Proefschrift Erasmus Universiteit Rotterdam.

Schmidt, E., Kuipers, B., Groeneveld, S., Fraussen, B., Ashikali, T., Laterveer, H. \& A. Slooff (2019). Publiek leiderschap en maatschappelijke meerwaarde. Den Haag: Leiden Leadership Centre, Universiteit Leiden.

Selznick, P. (1957). Leadership in administration: A sociological interpretation. Berkeley/Los Angeles, CA: Harper \& Row Publishers. 
Steen, M. van der, Scherpenisse, J., \& Twist, M. van. (2015). Sedimentatie in sturing: Systeem brengen in netwerkend werken door meervoudig organiseren. Den Haag: NSOB.

Studiegroep Openbaar Bestuur. (2016). Maak verschil: Krachtig inspelen op regionaal-economische opgaven. Den Haag.

Van de Walle, S. (2009). Overtolligheid en rommeligheid in publieke organisaties: Het belang van bricolage en improvisatie in innovatieve en crisisbestendige organisaties. Vlaams Tijdschrift voor Overheidsmanagement , (4), 71-80.

Weber, M. (1972). Wirtschaft und Gesellschaft: Grundriß der verstehenden Soziologie (fünfte, revidierte Auflage, besorgt von Johannes Winckelmann). Tübingen: Mohr (Paul Siebeck). 